\title{
A Neurobiological Perspective on Psychological Stress
}

\author{
Jayasankara Reddy. K and Unnati G Hunjan
}

\begin{abstract}
The last twenty years have been seen to extensive research on stress providing considerable insight into the biological basis of stress-fight and flight response, autonomic nervous systems and immune systems and cognitive functions interactions like attention, memory and creativity. Rapid change and development in the field of technology have made the world more competitive. This competency has made life more stressful. This paper encompasses the previous studies conducted till date on stress across the globe, based on neurobiology, sources and Impact of stress. An extensive literature search with key words stress, sources of stress, Impact of stress and coping strategies and have yielded many studies. In the present chapter we have focused on how stress affects the cognition, immune system and hormones. These articles were collected mainly from online databases EBSCO and ProQuest. The studies have shown that stressful situations reduce working memory, attention and concentration resulting in poor work efficiency/performance. The critical issues for future research have been identified and discussed based on the shortcomings from previous literature.

Index Terms - Stress; Neurobiology; Sources; Impact.
\end{abstract}

\section{INTRODUCTION}

Often in literature we find two ways of defining stress i.e. psychological stress and biological stress. Whereas Psychological stress occurs when an individual perceives that environmental demands tax or exceed his or her adaptive capacity [1] [2]; biological stress on the other hand has been defined as any change in the environment that changes or threatens to change and existing optimal steady state [3]. With a more holistic perspective however we shall describe stress from a psycho-biological perspective and define stress as any uncomfortable "emotional experience accompanied by predictable biochemical, physiological and behavioral changes."[4].

Reena had been constantly thinking about her upcoming graduate level final exam. She has been preparing for it since last week. But still a lot of portions to cover. Imagine her state on the previous day of a major test. A person who is close to her can identify various behaviour symptoms exhibited by her during the process of preparation. Being under stress is not a unique phenomenon. Everyone on a day to day basis experience's various kinds of stress. People report concerns about weight, health of a family member, rising prices, home maintenance, having too many things to do, money, crime, and physical appearance as the most frequent daily hassles they experience [5]. A qualitative study on Academic stress among students has shown that

\footnotetext{
Published on July 8, 2019.

Jayasankara Reddy $\mathrm{K}$ is with CHRIST (Deemed to be University), Bengaluru, Karnataka 560029 India (e-mail: jayasankara.reddy@ christuniversity.in).

Unnati G Hunjan is with CHRIST (Deemed to be University), Bengaluru, Karnataka 560029 India (e-mail: unnati.hunjan@christuniversity.in).
}

students exhibiting limited social interaction, alteration in eating habits and aggressive behaviour [6].

Stress has become one of the major topics of discussion among academicians and researchers since several years due to its special impact on various systems of the body. But people generally ask themselves a question what exactly is stress? In general terms it can be defined as the demands exerted on an individual to perform certain tasks. In the field of health psychology, stress arises when demand exceeds one's potential to resolve it. If an individual lack either internal or external demands to cope with the situation it becomes stressful. The following paragraphs discuss about the concept of stress, sources of stress, Impact of stress and the need for management.

\section{Conceptualization OF StREsS}

"Stress is a lifestyle crisis" [7] and can be any factor which acts internally or externally that helps the individual to adapt and to maintain the equilibrium [8]. Stress have been conceptualized in the literature based on three main viewpoints- stress as a response, stimulus and as a transaction [9]. It is considered to be a response of the body to a threatful stimuli in the response-based view [10]. Whereas in the stimulus-based view, stress is defined as events external to the individual such as life events which requires adjustment and adaptation [11]. Finally, in the transaction-based view, stress is a dynamic process of assigning meaning and coping based on person-environment transactions [12] [13].

Various physiological responses are associated with stress or stressful stimuli. To help the individual to cope with the stimuli these repertoires of responses play a vital role. These are maintained by two main biological systems. The first is the sympathetic division of the autonomic nervous system and the second is the brain-pituitary-adrenocortical axis [14]. Acute stressors stimulate the sympathetic adrenomedullary system and releases adrenalin. It plays a vital role in helping the individual to "fight or flight" [15].

The second major stress-responsive system is the brainpituitary-adrenocortical axis. This regulates the release of glucocorticoid (GC) hormones which mobilize energy into blood stream from the storage sites of the body [16]. Given such descriptions, stress is indeed a critical concern. It affects thoughts, feelings and finally behaviour in total. Excess stress causes problems and discomfort irrespective of age.

\section{SOURCES OF STRESS}

Literature have shown different forms of stress across age groups. Findings of [17] have shown that stress among college students was due to relationships and among married 
couples due to interpersonal conflicts [18]. These conflicts include spending money, balancing the work and family. Illness or divorce within family can also add to emotional and financial pressures. These can even give rise to problems like depression, anxiety and sadness [19]. The positive life events like marriage and arrival of a newborn can create stress due to financial pressures, sleep deprivation and difficulty in managing time.

In an organization an employ can feel stressed due to the work pressures of long working hours, deadlines, and unique responsibility [20]. People who are in helping professions with responsibility for saving people's lives, such as doctors, firefighters, and air traffic controllers, experiences high levels of stress because of the fear of making mistakes, due to its dreadful consequences [21]. Individuals experience stress due to environmental pressures such as noise, crowding, and natural disasters [22]. Another major cause of stress caused by one's environment is poverty, which can lead to other associated problems like crime, overcrowded housing, pollution, and noise [23] [24]. Finally, people often experience considerable amount of stress when they are in situations in which they lack control for example being stuck in a traffic jam, a long queue etc. can be so irritating.

\section{IMPACT OF STRESS}

During the stressful situation the individual's cognitive system becomes overloaded and it reduces his/her attentional resources [25]. Evidences suggest that reduced attentional resources under stress decreases the ability to filter out irrelevant information from relevant information [26]. Whereas under optimum stress level attention becomes more selective, which will be helpful for the task that requires exclusive focusing [27] [25].

Stress responses and the increased cortisol level influence memory and its components. Working memory gets impaired when the task load is high [28] and when the performance is evaluated during the stressful event [29]. Literature suggests that high levels of HPA axis activation due to high stress will impair memory consolidation [30] [31].

Stress has a direct link with immune system, chronic stress suppresses various immune system parameters. It has also been found that acute system also has an impact in immune functioning [2]. Specifically, it can trigger the production of immune system responses in the absence of an infectious agent [32]. Immune deficiency due to chronic exposure to stressors cause many physiological problems which includes heart and bowel disease, herpes, headaches and sleep difficulties [33] [5].

Studies have shown that stressful working atmosphere among students led them to exhibit various behavioral problems like decreased interest in academics, frequent school refusal, irritability, weeping spells and physical complaints due to stress [34] [35] [36] [37]. Excessive negative stress lead to reduced work efficiency which contributes to bad habits like addictions and substance abuse (CMHA, 2013). It can also lead to maladaptive behaviours like crime [38], absenteeism and school dropout [39] [40] [41].
It can be concluded from the studies that stressful situations reduce working memory [42], attention [26] and concentration [34] [26] resulting in poor work efficiency/performance [42] [43] [44] [45] [46]. Further, poor immune functioning makes individuals prone to illness, which reduces their ability to strive for excellence leading to reduced outcome. Increased stress negatively impacts cognition/immune functioning leading poor work efficiency this add on to further stress making it a recurring process [42] [46]. Thus, in this current scenario understanding and managing stress has a significant role to play.

\section{WHAT CAN BE DONE?}

The literature suggests about the various kinds of outcomes associated with stress. It can be seen from literature that stress leads to lower cognitive abilities and reduced work efficiency. The reference [6] points that individuals lack necessary skills for managing the same.

Planning effective interventions for individuals to cope with the stressful situations will have many fruitful results. The foremost outcome will be improvement in work efficiency. In a long run degradation in the health issues, suicidal rates and psychiatric illnesses too. Last but not least, if individuals acquire necessary skills for management they can contribute positively for the development of economy.

\section{REFERENCES}

[1] Cohen S, Kessler R.C., Gordon U.L. (1995) Strategies for measuring stress in studies of psychiatric and physical disorder. In: Cohen $\mathrm{S}$, Kessler RC, Gordon UL, eds. Measuring Stress: A Guide for Health and Social Scientists. New York, NY: Oxford University Press: 3-26.

[2] McEwen, B. S. (2000). The neurobiology of stress: from serendipity to clinical relevance. Brain research, 886(1), 172-189.

[3] Barrett, A. M. (2011). An education Millennium Development Goal for quality: complexity and democracy. Compare, 41(1), 145-148.

[4] Baum, A. (1990). Stress, intrusive imagery, and chronic distress. Health psychology, 9(6), 653.

[5] Sanderson, C. A. (2013). Health psychology (2nd Ed). Wiley Global Education.

[6] Reddy, J., Keshu, M., Thomas, S., \&Dey, A. M. (2016). Cognitive and cultural aspects of academic stress: a review. International Education and Research Journal, 2(1), 80-85.

[7] Masih, P. P., \&Gulrez, N. K. (2006). Age and gender differences on stress. Recent trends in human stress management, 97-104.

[8] Stevens, R. E., Loudon, D. L., Yow, D. A., Bowden, W. W., \& Humphrey, J. H. (2013). Stress in college athletics: Causes, consequences, coping. Routledge.

[9] Hill, R. (1958). Generic features of families under stress. Social casework. 39, 139-150

[10] Selye, H. (1956). The stress of life. New York, NY, US: McGraw-Hill

[11] Holmes, T. H., \&Rahe, R. H. (1967). The social readjustment rating scale.Journal of psychosomatic research, 11(2), 213-218.

[12] Lazarus, R. S. (1991). Progress on a cognitive-motivational-relational theory of emotion. American psychologist, 46(8), 819.

[13] Lazarus, R. S., \& Folkman, S. (1984). Stress. Appraisal, and coping, 725.

[14] Bourne, L. E., \&Yaroush, R. A. (2003). Stress and cognition: A cognitive psychological perspective. Unpublished manuscript, NASA grant NAG2-1561.

[15] Cannon, W. B. (1932). The wisdom of the body. New York, NY, US: W W Norton \& Co

[16] Akil, H., Campeau, S., Cullinan, W. E., Lechan, R. M., Toni, R., Watson, S. J., \& Moore, R. M. (1999). Neuroendocrine systems I: Overview, thyroid and adrenal axes.

[17] Ptacek, J. T., Smith, R. E., \&Zanas, J. (1992). Gender, appraisal, and coping: A longitudinal analysis. Journal of Personality, 60, 747-770. 
[18] Bolger, N., DeLongis, A., Kessler, R. C., \& Schilling, E. A. (1989). Effects of daily stress on negative mood. Journal of Personality and Social Psychology, 57, 808-818.

[19] Kiecolt-Glaser, J. K., Dura, J. R., Speicher, C. E.,Trask, O. J., \& Glaser, R. (1991). Spousal caregivers of dementia victims: Longitudinal changes in immunity and health. Psychosomatic Medicine, 53, 345-362.

[20] Spector, P. E. (2002). Employee control and occupational stress. Current Directions in Psychological Science, 11, 133-136.

[21] Shouksmith, G., \& Taylor, J. E. (1997). The interaction of culture with general job stressors in air traffic controllers. International Journal of Aviation Psychology, 7, 343-352

[22] Evans, G. W., Bullinger, M., \&Hygge, S. (1998). Chronic noise exposure and physiological response: A prospective study of children living under environmental stress. Psychological Science, 9, 75-77.

[23] Johnson, C. J., Heckman, T. G., Hansen, N. B.,Kochman, A. \&Sikkema, K.J. (2009). Adherence to antiretroviral medication in older adults living with HIV/AIDS: A comparison of alternative models. AIDS Care, 21, 541-551.

[24] Myers, H. F., Kagawa-Singer, M., Kumanika, S.K., Lex, B. W., \&Markides, C. S. (1995). Panel III: Behavioral risk factors related to chronic disease in ethnic minorities. Health Psychology, 14, 613-621

[25] Chajut, E., \&Algom, D. (2003). Selective attention improves under stress: implications for theories of social cognition. Journal of personality and social psychology, 85(2), 231

[26] Skosnik, Patrick D., Robert T. Chatterton, Tara Swisher, and Sohee Park. "Modulation of attentional inhibition by norepinephrine and cortisol after psychological stress." International Journal of Psychophysiology 36 (1), 59-68.

[27] Braunstein-bercovitz, H. (2003). Does stress enhance or impair selective attention? The effects of stress and perceptual load on negative priming. Anxiety, stress, and coping, 16(4), 345357.

[28] Lupien, S. J., Gillin, C. J., \&Hauger, R. L. (1999). Working memory is more sensitive than declarative memory to the acute effects of corticosteroids: A dose-response study in humans. Behavioral neuroscience, 113(3), 420 .

[29] Elzinga, B. M., \&Roelofs, K. (2005). Cortisol-induced impairments of working memory require acute sympathetic activation. Behavioral neuroscience, 119(1), 98

[30] Abercrombie, H. C., Kalin, N. H., Thurow, M. E., Rosenkranz, M. A., \& Davidson, R. J. (2003). Cortisol variation in humans affects memory for emotionally laden and neutral information. Behavioral neuroscience, 117(3), 505.

[31] Erickson, K., Drevets, W., \&Schulkin, J. (2003). Glucocorticoid regulation of diverse cognitive functions in normal and pathological emotional states.Neuroscience\&Biobehavioral Reviews, 27(3), 233 246.

[32] Nguyen, K. T., Deak, T., Owens, S. M., Kohno, T., Fleshner, M., Watkins, L. R., \& Maier, S. F. (1998). Exposure to acute stress induces brain interleukin-1 $\beta$ protein in the rat. The Journal of neuroscience, 18(6), 2239-2246.

[33] Glanz, K., \& Schwartz, M. D. (2008). Stress, coping, and health behavior.Health behavior and health education: Theory, research, and practice, 4, 211-236.

[34] Chan, K. Y., Hung, E. C. S., Pin, H. Y., \&Ithnin, H. B. (1999). Stress among medical students in a medical college of South India/Commentary. Education for Health, 12(1), 63.

[35] Rangaswamy, K. (1982). Tension headache in adolescents. Journal of Psychological Researches. 26(2), 70-72

[36] Deb, S., Strodl, E., \& Sun, J. (2015). Academic stress, parental pressure, anxiety and mental health among Indian high schoo students. International Journal of Psychology and Behavioral Sciences, 5(1), 26-34.

[37] Verma, S., Sharma, D., \& Larson, R. W. (2002). School stress in India: Effects on time and daily emotions. International Journal of Behavioral Development, 26(6), 500-508.

[38] Reddy, K. J., Menon, K. R., \& Hunjan, U. G. (2018). Neurobiological Aspects of Violent and Criminal Behaviour: Deficits in Frontal Lobe Function and Neurotransmitters 1. International Journal of Criminal Justice Sciences, 13(1), 44

[39] Dusselier, L., Dunn, B., Wang, Y., Shelley, M. C., \& Whalen, D. F. (2005). Personal, health, academic, and environmental predictors of stress for residence hall students. Journal of American college health 54(1), 15-24.

[40] Glanz, K., \& Schwartz, M. D. (2008). Stress, coping, and health behavior. Health behavior and health education, 211-236

[41] Buchanan, T. W., Tranel, D., \&Adolphs, R. (2006). Impaired memory retrieval correlates with individual differences in cortisol response but not autonomic response. Learning \& Memory, 13(3), 382-387

[42] American College Health Association. (2009). American College Health Association-national college health assessment II: Reference group executive summary fall 2009. Linthicum, MD: American College Health Association.

[43] Cave, D. (2011). Student health at the University of Alberta: A Report of Findings from the 2011 UofA National College Health Assessment. Retrieved from http://www.su.ualberta.ca/media/uploads/assets/CouncilPresentations/ NCHA\%20report\%20January\%2026:2012.pdf

[44] Chow, H. P. (2007). Psychological well-being and scholastic achievement among university students in a Canadian Prairie City. Social Psychology of Education, 10(4), 483-493.

[45] Chung, K. F., \& Cheung, M. M. (2008). Sleep-wake patterns and sleep disturbance among Hong Kong Chinese adolescents. Sleep, $31(2), 185$

[46] Canadian Association of College \& University Student Services and Canadian Mental Health Association (CMHA) (2013). PostSecondary Student Mental Health: Guide to a Systemic Approach. Vancouver, BC: Retrieved from http://www.cacuss.ca/_Library/documents/PSSMH_GuideToSystemi cApproach_CACU S-CMHA_2013.pdf

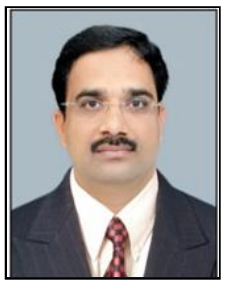

Dr. K. Jayasankara Reddy completed his M. Sc in Psychology and Ph.D. in Psychology in the area of Neuro Psychology from Sri Venkateshwara University, Tirupathi, India. He also did his Post graduate program in Clinical Neurophysiology from the faculty of Medicine, Department of Neuro Sciences, Sri Venkateshwara Institute of Medical sciences University, Tirupathi, India. Presently working as a Professor of Psychology (Health \& Neuro Psychology), Christ University, Bangalore.

He has a span of 17 years of experience in academic, research and consulting in child and adult Neuropsychology and in neuro electrophysiology. He has contributed more than 50 research articles, which are published in various Journals and conference proceedings. He has presented more than 30 research papers in various National and International conferences. He has received three times Best Research Paper Award in the area of Neuro Psychology in various National and International conferences. Further, he has delivered key-note address, panel discussions and invited talks in various International/ National Seminars/Workshops/Conferences and acted as a Resource Person for Refresher Courses in various colleges and conferences.

Dr. Reddy is the recipient of Indian School Psychology Association (InSPA) - Best Performance Award - 2017 for his valuable services and contributions to the promotion of school psychology in India. Also received ISMA- Research Award 2017 in recognition of positive contribution to the subject of Stress Management from the International Stress Management Association (ISMA)

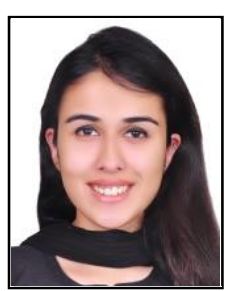

Unnati G Hunjan has completed her M.Sc. in Clinical Psychology from CHRIST (Deemed to be University), Bangalore. She is currently pursuing her Ph.D. Psychology in the field of neuropsychology and animal-assisted therapy from CHRIST (Deemed to be University), Bangalore.

She is an Assistant Professor in the Department of Psychology at CHRIST. She has presented papers and delivered keynote addresses and invited for talks at various national and international platforms. Her research interest including studying neuropsychological aspects, especially in relation to animal-assisted therapies. She has also been the recipient of scholarships for international events. 